\title{
Causes and Mitigation Strategies for Post-Harvest Losses in Agriculture
}

\author{
Anuj Tripathi* \\ Nuclear Agriculture and Biotechnology Division, Bhabha Atomic Research Centre, Mumbai, India
}

*Corresponding Author: Anuj Tripathi, Nuclear Agriculture and Biotechnology Division, Bhabha Atomic Research Centre, Mumbai, India.

Received: April 24, 2019; Published: September 01, 2019

DOI: 10.31080/ASAG.2019.03.0635

Sustainable agriculture is the basic need of a country for the food security. It plays a key role in the economic performance and significant contribution to the gross domestic products (GDP) of a country. Additionally, productive growth in agriculture sector remarkably alleviates poverty and generates employments to the larger population. Therefore, management of agriculture products is of great importance. In general, traditional and unsatisfactory customs is a major setback for resourceful productivity because of a large gap between the field production and actual yield. There are several pre-harvesting factors (like, poor quality seeds, inadequate farming practices, attack of pests) that can affect the crop productivity, however, we are focusing here only with the causes and mitigation strategies of losses after the harvest. Agriculture sector has a great challenge to reduce the post-harvest losses. For example, a grain undergoes a series of processing which leads to various physical and biochemical alteration of grain in the post harvest. These quantity and quality dependents post harvest losses amend the nether use of product which causes increased gross economic loss compared to the given inputs that includes raw materials, chemical resources, cultivation, work hours etc. Farmers are facing high economic loss because limited technical know-how on advanced scientific agricultural practices of crop harvesting, inappropriate storage procedures reduces shelf-life, which leads to the poor quality and colossal loss of food. Some crops are highly vulnerable to post-harvest loss (like vegetables, fruits and other perishable crops) due to high water content and subjected to desiccation and mechanical injury. Therefore, a special attention is required to these crops during harvesting and transportation for longer shelf-life. The major issues which are responsible for post-harvest losses are premature harvesting, poor threshing, insufficient drying and cleaning, pest, rodent and bird attack, and also due to improper packaging, storage and transportation of bulk commodity. Importantly, small land farmers ( $\sim 80 \%$ in India of total farming community) are affected by the challenges of fragmentation of agricultural landholdings and value chain inefficiencies (i.e. low investment in agriculture, low productivity, poor access to markets and low income). It is estimated that only in India, the economic burden of post harvest losses is approximately INR 926 billion per year.

The importance and suitability of advanced and optimized agricultural procedures (selection of planting materials, culturing and handling including harvesting has been reported for the quality agriculture produce. Thus, appropriate agriculture infrastructure with general principles of extending shelf-life of crops must be followed at various stages in order to minimize post harvest losses. Mechanical injuries like bruises, scratches, cuts are needed to be minimized by appointing skilled workers and advanced harvesting equipment's. Harvesting is suggested to be performed at the appropriate maturation stage of a crop in the cool part of a day to avoid stress. Proper handling of crops, fruits and vegetables, their sorting, hygienization/sterilization, and packaging for transportation or bulk commodity transportation and delay in distribution are some of the important aspects for minimizing the post harvest losses. For example, crop specific model systems for their transportation should be established which can take care of loading, unloading, temperature management, physical stress etc. for a particular crop. These causes has an impact on losses and burden to the economic gain to all those involved in the chain. The magnitude of loss that occur from field to the fork leads a concern of food security, therefore, educational and training programs must be organized for producers, buyers, traders, middlemen and consumers that could provide a appropriate awareness to mitigate the losses at the field, on-road, and bulk/retailer storage conditions. It is expected that dynamism in the awareness programs will drive efficiencies across key value chains by collective participation of government and industrial partners which will lead to reduction in post harvest losses and improvements in livelihoods of small farmers.

\section{Volume 3 Issue 10 October 2019 \\ (C) All rights are reserved by Anuj Tripathi.}

